\title{
Corrigendum
}

\section{Trace element concentration in organic and conventional milk: what are the nutritional implications of the recently reported differences? - CORRIGENDUM}

Sarah C. Bath and Margaret P. Rayman

(First published online 24 November 2016)

DOI: http://dx.doi.org/10.1017/S0007114516001616

Original text and correction

On page 2 - fourth paragraph, it currently says 'Indeed, it has been suggested that the goitrogenic potential of fresh forage is lower than that of feed given in the winter ${ }^{(25)}$. This should read 'Indeed, it has been suggested that the goitrogenic potential of fresh forage is higher than that of feed given in the winter ${ }^{(25)}$, (i.e. higher not lower). 